\title{
Analysis for Industrial Grid Containing Nonlinear Loads
}

\author{
Basim Mohammed Al Kadhimi \\ Lecturer-electrical eng. Dep. - college of engineering - wasit university
}

\begin{abstract}
Harmonics is the most important issue among all issues related to the power quality. Harmonics comes from different non-linear loads like uninterruptible power supplies systems (UPS), variable speed motor drives, rectifiers, personal computers, adjustable speed drives, fluorescent lighting, rectifier banks, data processing loads, arc furnaces, and so on. Simulation of a real power supply system that consists of linear loads and nonlinear loads as variable speed drives has been carried out in the work. Variable speed drives generate harmonics into supply system that contains different values of compensated capacitors. Calculations of equivalent system reactance for generated harmonics, voltage harmonics, voltage harmonics in percentage, THD (Total Harmonic Distortion) of voltage, frequency characteristics, current flows in the system capacitor units have been worked out using Mathcad software. The obtained results have been compared with the European Standard (EN 50160) for supply quality requirements of the European Union.
\end{abstract}

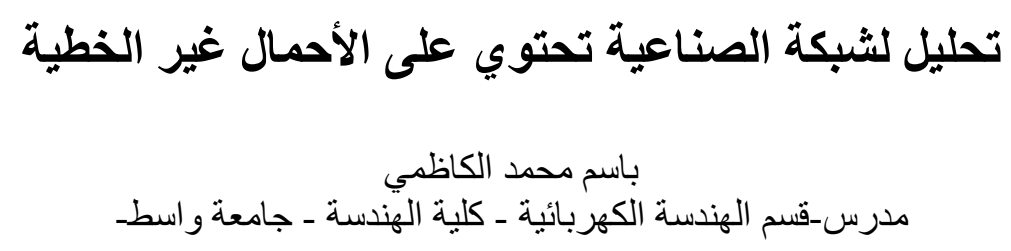

الخلاصة

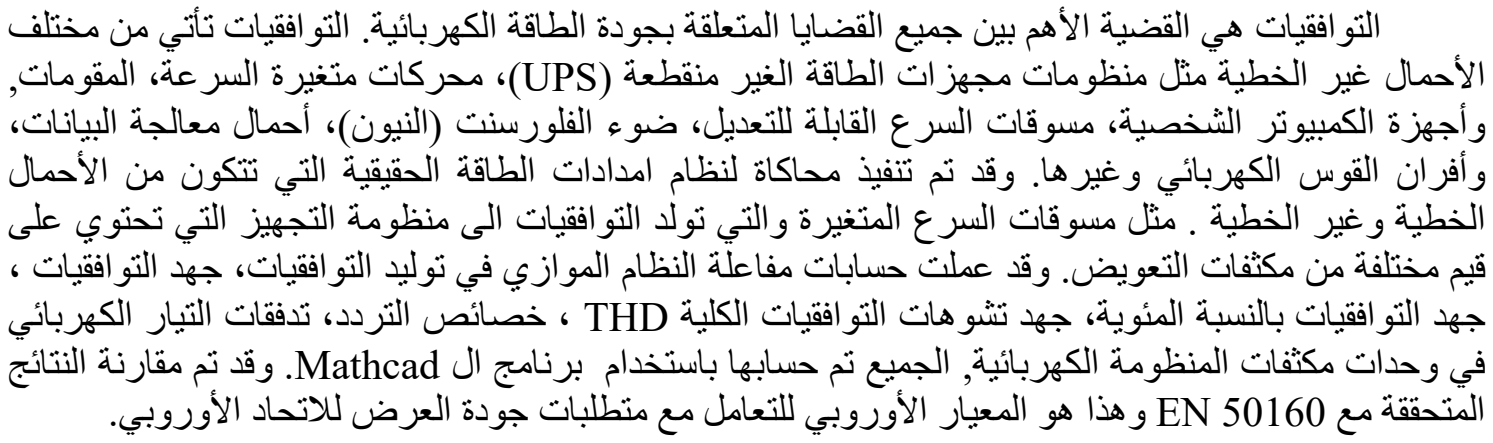




\section{Introduction}

\section{Harmonics, Definitions, Terminology, and Analysis}

\section{Definition of harmonics}

Webster's New World Dictionary defines harmonics as pure tones making up a composite tone in music. A pure tone is a musical sound of a single frequency, and a combination of many pure tones makes up a composite sound. Sound waves are electromagnetic waves traveling through space as a periodic function of time. Can the principle behind pure music tones apply to other functions or quantities that are time dependent? In the early 1800s, French mathematician, Jean Baptiste Fourier formulated that a periodic non-sinusoidal function of a fundamental frequency $f$ may be expressed as the sum of sinusoidal functions of frequencies which are multiples of the fundamental frequency. In our discussions here, we are mainly concerned with periodic functions of voltage and current due to their importance in the field of power quality. In other applications, the periodic function might refer to radio frequency transmission, heat flow through a medium, vibrations of a mechanical structure, or the motions of a pendulum in a clock.

A sinusoidal voltage or current function that is dependent on time $t$ may be represented by the following expressions [1]:

$$
\begin{aligned}
& \text { Voltage function, } \mathrm{v}(\mathrm{t})=\mathrm{V} \sin (\omega \mathrm{t}) \\
& \text { Current function, } \mathrm{i}(\mathrm{t})=\mathrm{I} \sin (\omega \mathrm{t} \pm \theta)
\end{aligned}
$$

Where $\omega=2 \pi f$, is known as the angular velocity of the periodic waveform and $\theta$ is the difference in phase angle between the voltage and the current waveforms referred to as a common axis. The sign of phase angle $\theta$ is positive if the current leads the voltage and negative if the current lags the voltage.

Figure 1 contains voltage and current waveforms expressed by the equation( 1 ) and ( 2 ) and which by definition are pure sinusoids. For the periodic non- sinusoidal waveform has shown in Figure 2 .

the simplified Fourier expression states:

$$
\mathrm{v}(\mathrm{t})=\mathrm{V}_{1} \sin (\omega \mathrm{t})+\mathrm{V}_{2} \sin (2 \omega \mathrm{t})+\ldots+\mathrm{V}_{\mathrm{n}} \sin (\mathrm{n} \omega \mathrm{t})
$$

The Fourier expression is an infinite series. In this equation, $\mathrm{V}_{1}, \mathrm{~V}_{2}, \mathrm{~V}_{3}, \ldots, \mathrm{V}_{\mathrm{n}}$ are the peak values of the successive terms of the expression. The terms are known as the harmonics of the periodic waveform. The fundamental (or first harmonic) frequency has a Lagging functions are indicated by negative phase angle and leading functions by positive phase angle 


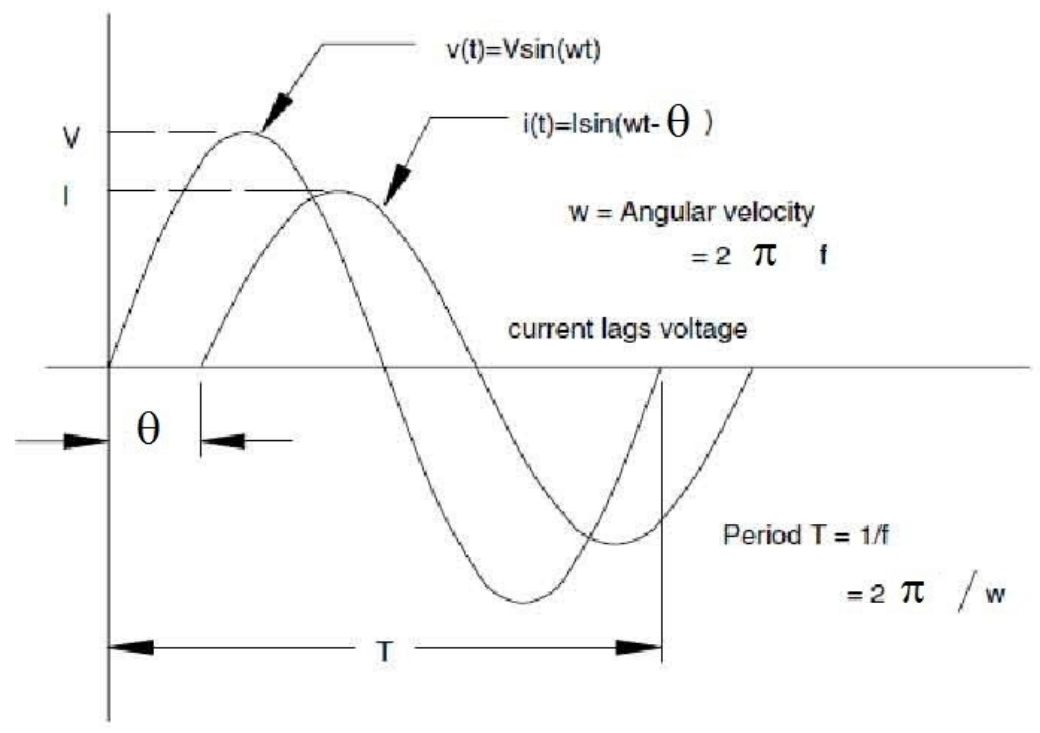

Figure 1 - Sinusoidal voltage and current functions of time

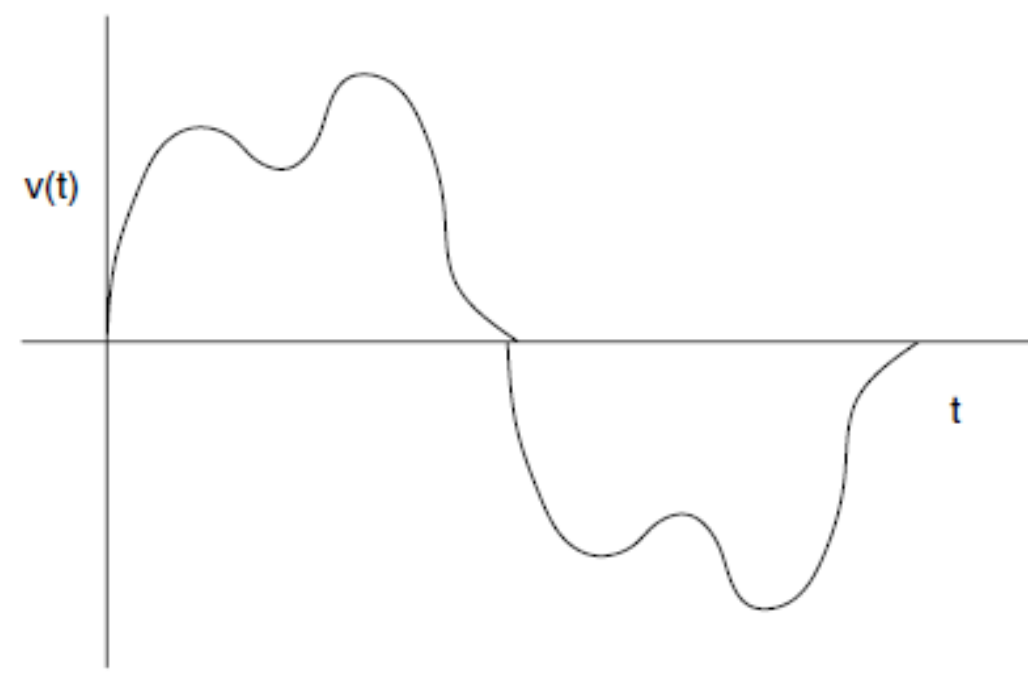

Figure 2 - Nonsinusoidal voltage waveform Fourier series

Harmonics is the most important issue among all issues related to power quality. To analyze harmonics in the power system, different new standards and definition shave been introduced; for example, harmonic distortion factors of voltage and current waveform. However, the basis of all harmonic assessment still depends on the measurement of amplitude and phase angle of the harmonics components. Order of harmonics present in the system may be integer or non-integer multiple of the 
fundamental component. A lot of research is going on from the very past to assess both of these types of harmonics. Different mathematical tools have come out for this purpose. Some of them are capable of measuring both integer and non-integer order of harmonics. Some of them are capable of measuring only integer type of harmonics .Also, in many cases, signals could not be captured in continuous form. To overcome these limitations modified mathematical tools have been developed to handle discrete signals [3]. Mathematical tools for harmonics analysis may be in a time domain, or frequency domain or both time-frequency domains. Thus broadly, frequency assessment can be categories as follows:

1. Fourier Transform Based Assessment: One of the old techniques used in the analysis of non-sinusoidal signals is Fourier transform. Fourier analysis has been used for power quality assessment for a long period. It permits mapping of signal From time domain to frequency domain by decomposing the signals into several frequency components. Application of Discrete FT and Fast FT are very useful to overcome some of the disadvantages of the earlier one [1].

2. Wavelet Transform Based Assessment: Fourier transform fails in the analysis of transients owing to the non-stationary property of its signals in both time and frequency domains. The Wavelet transform (WT) helps us in such cases. Wavelet analysis has been suggested as a new tool for measurement and monitoring power quality problems both in absence and presence of transients. Multi-resolution signal decomposition has been used to localize different power quality problems and assess them.

3. Neuro-Fuzzy Based Assessment: An ANN-fuzzy logic combined system for classifying power system disturbances are used to identify the event based quality issues. Fuzzy-Based Adaptive Digital Metering system and Genetic Algorithm have been introduced to avoid effects of power quality problems.

\section{- Fourier Series}

Baron Jean - Baptiste - Joseph Fourier used to believe that any arbitrary defined function could be expressed in a single analytical expression. Incidentally, the idea was introduced much before by Leonhard Euler. In this relation, Euler published a formula:

$$
1 / 2 x=\sin x-1 / 2 \sin 2 x+1 / 3 \sin 3 x+\cdots
$$

Fourier expands continuous, single valued function of the time domain in terms of DC component, and series of integer harmonics in 1822 [4-5].

As, power system voltage and current signals often consist of harmonics as well as DC components, postulate given by Fourier is frequently used to express them in terms of Fourier series. If $f(\mathrm{t})$ be a time domain continuous periodic function, then it can be expressed as:

$$
f(t)=a \circ+\sum_{n=1,2,3, \ldots} a_{n} \cos n w t+\sum_{n=1,2,3, \ldots} b_{n} \sin n w t
$$

\section{- Fourier Transform}

Time domain single valued, periodic and continuous function $f(\mathrm{t})$ can be transformed into frequency domain by Fourier transformation method $[4,5]$. 


$$
F(f)=\int_{-\infty}^{+\infty} f(t) * e^{-j 2 \pi f t} d t
$$

Provided:

1. The function $f(\mathrm{t})$ is single-valued and continuous in well-defined time interval T.

2. There is no discontinuity in time $\mathrm{T}$, if there is any discontinuity, and then it will be finite.

3. Number of maximum in time $\mathrm{T}$ is finite.

By Fourier transform, a time domain function can be expressed in the frequency domain. The method is widely used to handle the continuous signal in frequency domain. However, the transform method suffers from limitation to handle discrete or discontinuous, multi-valued and undefined signals which are often faced by electrical applications.

\section{-Discrete Fourier Transform}

Most of the measurements of electrical parameters face signals in discrete forms which could not be analyzed by Fourier transform. Signals are available in the form of series of independent numerical values at discrete intervals. To deals with such discrete signals, Fourier transform (FT) is modified as discrete Fourier transforms (DFT). Frequency domain spectrums of a time domain function $f(\mathrm{t})$ obtained by DFT is given as:

$$
F(F k)=\frac{1}{n} * \sum_{n=0}^{n-1} f(t n) * e^{\frac{j 2 \pi k n}{n}}
$$

$\mathrm{n}$ is the total number of samples in one period. Here both time domain function and frequency domain spectrum are periodic. The frequency domain spectrums depend on the nature of sampling by which signals are being captured for measurement and analysis. However, the DFT suffers from the main limitation of high execution time for large values of $n$.

\section{Fast Fourier Transform}

The limitation of DFT is overcome by Fast Fourier transform (FFT) [4]. By FFT, the matrix for multiplication required in DFT is resolved into many simpler forms. This reduces the multiplication process as well as the time of execution. This finds a wide application area of FFT in measurement and analysis of frequency domain spectrum, specially, for electric signals which are captured in discrete form, Fourier transform is then upgraded to short time Fourier transform which deals with the wave dividing the time span into many short periods. The Fourier series allows expression of nonsinusoidal periodic waveforms in terms of sinusoidal harmonic frequency component Frequency of $f$, the second harmonic has a frequency of $2 \times f$, the third harmonic has a frequency of $3 \times f$, and the $\mathrm{n}$-th harmonic has a frequency of $\mathrm{n} \times f$. 
If the fundamental frequency is $60 \mathrm{~Hz}$ (as in the U.S.), the second harmonic frequency is $120 \mathrm{~Hz}$, and the third harmonic frequency is $180 \mathrm{~Hz}$. The second harmonic undergoes two complete cycles during one cycle of the fundamental frequency, and the third harmonic traverses three complete cycles during one cycle of the fundamental frequency. $\mathrm{V}_{1}, \mathrm{~V}_{2}$, and $\mathrm{V}_{3}$ are the peak values of the harmonic components that comprise the composite waveform, which also has a frequency of $f$. The ability to express a non-sinusoidal waveform as a sum of sinusoidal waves allows us to use the more common mathematical expressions and formulas to solve power system problems. In order to find the effect of a non-sinusoidal voltage or current on a piece of equipment, we only need to determine the effect of the individual harmonics and then vectorially sum the results to derive the net effect. Figure 4 illustrates how individual harmonics that are sinusoidal can be added to form a non-sinusoidal waveform.

The Fourier expression in Eq. (8) has been simplified to clarify the concept behind harmonic frequency components in a nonlinear periodic function. For the purist, the following more precise expression is offered. For a periodic voltage wave with fundamental frequency of $\omega=2 \pi f$,

$$
v(t)=\sum\left(a_{n} \cos n \omega t+b_{n} \sin n \omega t\right)(\text { for } n=1 \text { to } \infty)
$$

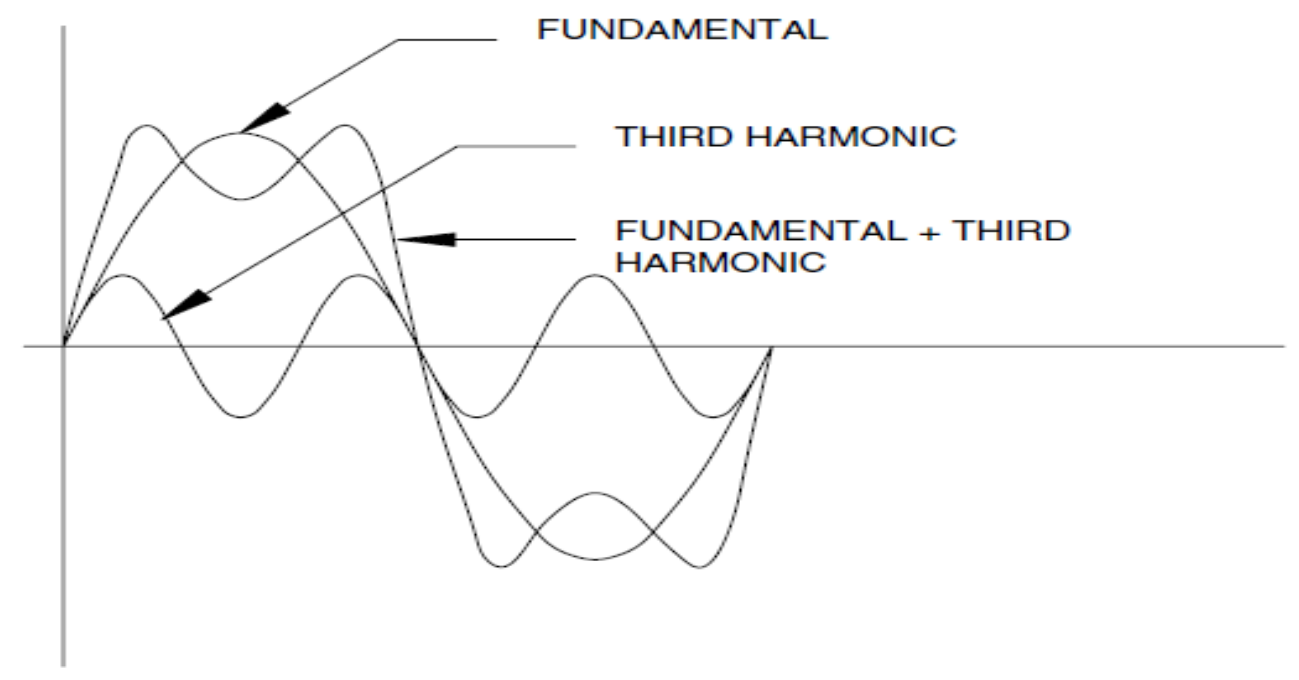

Figure 3- Creation of nonlinear waveform by adding the fundamental and third harmonic frequency waveform

Where $a_{n}$ and $b_{n}$ are the coefficients of the individual harmonic terms or components. Under certain conditions, the cosine or sine terms can vanish, giving us a simpler expression. If the function is an even function, meaning $f(-t)=f(t)$, then the sine terms vanish from the expression.

If the function is odd, with $f(-t)=-f(t)$, then the cosine terms disappear. For our analysis, we will use the simplified expression involving sine terms only. It 
should be noted that having both sine and cosine terms affects only the displacement angle of the harmonic components and the shape of the nonlinear wave and does not alter the principle behind the application of the Fourier series.

The coefficients of the harmonic terms of a function $f(t)$ contained in Eq. (8) are determined by:

$$
\begin{gathered}
a_{n}=\frac{1}{\pi} \int_{+\pi}^{-\pi} f(t) * \cos n t * d t,(n=1,2,3, \ldots \ldots) a_{k}= \\
\frac{1}{\pi} \int_{+\pi}^{-\pi} f(t) * \operatorname{coskt}^{*} d t,(k=1,2,3, \ldots \ldots, n) a_{k}=\frac{1}{\pi} \int_{+\pi}^{-\pi} f(t) * \operatorname{coskt}^{*} d t,(k= \\
1,2,3, \ldots \ldots, n) a k=\frac{1}{\pi} \int_{+\pi}^{-\pi} f(t) * \operatorname{coskt} t^{*} d,(k=1,2,3, \ldots \ldots, n) \\
a_{n}=\frac{1}{\pi} \int_{+\pi}^{-\pi} f(t) * \operatorname{sinnt} * d t,(n=1,2,3, \ldots \ldots)
\end{gathered}
$$

The coefficients represent the peak values of the individual harmonic frequency terms of the nonlinear periodic function represented by $f(t)[1]$.

\section{3- Causes of voltage and current harmonics}

A pure sinusoidal waveform with zero harmonic distortion is a hypothetical quantity and not a practical one. The voltage waveform, even at the point of generation, contains a small amount of distortion due to non-uniformity in the excitation magnetic Field and discrete spatial distribution of coils around the generator stator slots. The distortion at the point of generation is usually very low, typically less than $1.0 \%$. The generated voltage is transmitted many hundreds of miles, transformed to several levels, and ultimately distributed to the power user. The user equipment generates currents that are rich in harmonic frequency components, As harmonic currents travel to the power source, the current distortion results in additional voltage distortion due to impedance voltages associated with the various power distribution equipment, such as transmission and distribution lines, transformers, cables, buses, and so on . Figure 4 illustrates how current distortion is transformed into voltage distortion. Not all voltage distortion, however, is due to the flow of distorted current through the power system impedance. For instance, static uninterruptible power source (UPS) systems can generate appreciable voltage distortion due to the nature of their operation. Normal AC voltage is converted to DC and then reconverted to AC in the inverter section of the UPS. Unless waveform shaping circuitry is provided, the voltage waveforms generated in UPS units tend to be distorted. As nonlinear loads are propagated into the power system, voltage distortions are introduced which become greater moving from the source to the load because of the circuit impedances. Current distortions, for the most part, are caused by loads. 


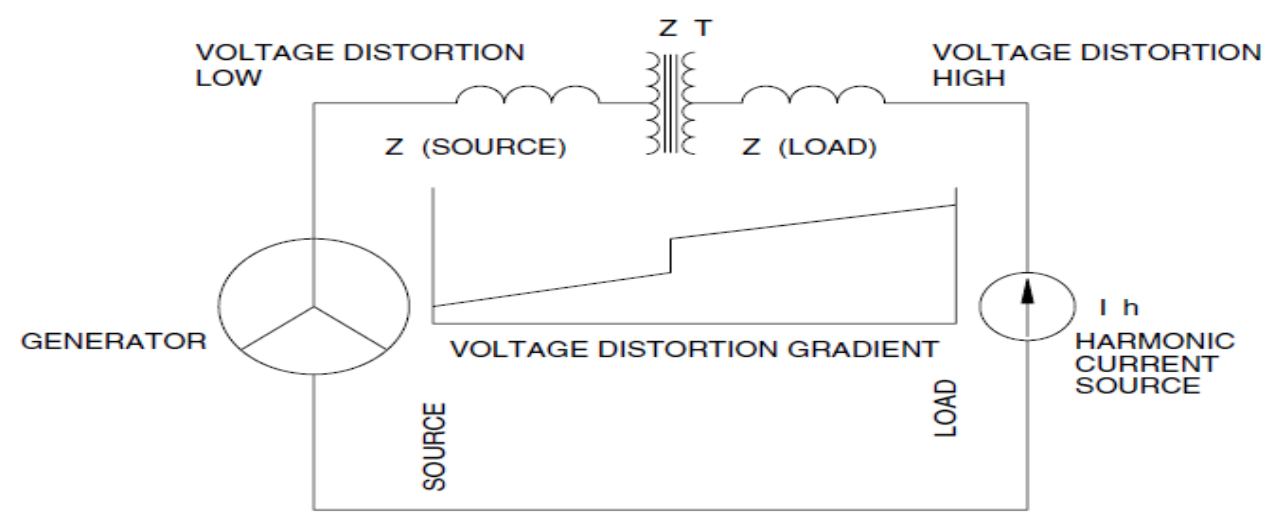

Figure 4 - Voltage distortion due to current distortion. The gradient graph indicates how distortion changes from source to load

Even loads that are linear will generate nonlinear currents if the supply voltage waveform is significantly distorted. When several power users share a common power line, the voltage distortion produced by harmonic current injection of one user can affect the other users. This is why standards are being issued that will limit the amount of harmonic currents that individual power users can feed into the source. The major causes of current distortion are nonlinear loads due to adjustable speed drives, fluorescent lighting, rectifier banks, computer and data processing loads, arc furnaces, and so on One can easily visualize an environment where a wide spectrum of harmonic frequencies are generated and transmitted to other loads or other power users, thereby producing undesirable results throughout the system [1].

\section{Power quality indices under harmonic distortion}

\subsection{Total harmonic distortion}

Total harmonic distortion (THD) is an important index widely used to describe power quality issues in transmission and distribution systems. It considers the contribution of every individual harmonic component on the signal.

THD is defined for voltage and current signals, respectively, as follows[2]:

$$
\begin{aligned}
& T H D_{v}=\frac{\sqrt{\sum_{n=2}^{\infty} V_{n}^{2}}}{V_{1}}
\end{aligned}
$$

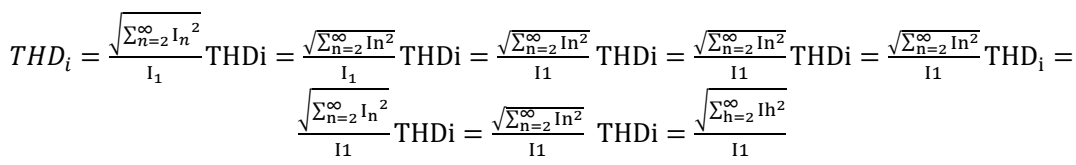

This means that the ratio between Rms values of signals including harmonics and signals considering only the fundamental frequency define the total harmonic 
distortion [2] .

\subsection{Total demand distortion}

Harmonic distortion is most meaningful when monitored at the point of common coupling (PCC) usually the customer's metering point over a period that can reflect maximum customer demand. Weak sources with a large demand current relative to their rated current will tend to show greater waveform distortion. Conversely, stiff sources characterized for operating at low demand currents will show decreased waveform distortion. The total demand distortion is based on the demand current $\mathrm{I}_{\mathrm{L}}[2]$.

\subsection{Displacement, Distortion, and Total Power Factor}

With an increasing harmonic distortion environment, the conventional definition of power factor as the cosine of the angle between fundamental frequency voltage and current has progressed to consider the signal's Rms values, which make up the contribution of components of different frequencies. Thus, displacement power factor (DPF) continues to characterize the power frequency factor while distortion (or true) power factor $(\mathrm{TPF})$ emerges as the index that tracks $\mathrm{Rms}$ signal variations. $\left(\mathrm{PF}_{\text {total }}\right)$ thus becomes the product of distortion and true power factors:

$$
\begin{aligned}
& \mathrm{K}=\frac{\sum_{\mathrm{h}=1}^{\infty}\left(\frac{\mathrm{Ih}}{\mathrm{I}}\right)^{2}{ }^{2} \mathrm{~h}^{2}}{\sum_{\mathrm{h}=1}^{\infty}\left(\frac{\mathrm{Ih}}{\mathrm{I} 1}\right)^{2}}=\mathrm{PF}_{\text {total }}=\mathrm{DFT} * \mathrm{TPF}=\cos \left(\theta_{1}-\delta_{1}\right) * \frac{\mathrm{P}_{\text {total }}}{\mathrm{S}_{\text {total }}} \\
& =\left(\frac{\mathrm{P}_{1}}{\mathrm{~V}_{1} \mathrm{I}_{1}}\right)\left[\frac{\sum_{\mathrm{n}=1}^{\infty} \mathrm{I}_{\mathrm{n}} \mathrm{V}_{\mathrm{n}} \cos \left(\theta_{\mathrm{n}}-\delta_{\mathrm{n}}\right)}{\sqrt{\sum_{\mathrm{n}=1}^{\infty}\left(\mathrm{V}_{\mathrm{n}}\right)^{2}} \sqrt{\sum_{\mathrm{n}=1}^{\infty}\left(\mathrm{I}_{\mathrm{n}}\right)^{2}}}\right]= \\
& =\left(\frac{\mathrm{P}_{1}}{\mathrm{~V}_{1} \mathrm{I}_{1}}\right) \sqrt{\frac{1}{1+\left(\frac{\mathrm{THD}_{\mathrm{i}}}{100}\right)^{2}}} \\
& \mathrm{~K}=\frac{\sum_{\mathrm{n}=1}^{\infty}\left(\frac{\mathrm{I}_{\mathrm{n}}}{\mathrm{I}_{1}}\right)^{2} * \mathrm{n}^{2}}{\sum_{\mathrm{n}=1}^{\infty}\left(\frac{\mathrm{I}_{\mathrm{n}}}{\mathrm{I}_{1}}\right)^{2}}=\sum_{\mathrm{n}=1}^{\infty}\left[\mathrm{I}_{\mathrm{n}} *\left(\mathrm{P}_{\mathrm{u}}\right)\right]^{2 * \mathrm{n}^{2}} \sum_{\mathrm{h}=1}^{\infty}[\mathrm{In} *(\mathrm{pu})]^{2 *} \mathrm{n}^{2}
\end{aligned}
$$

where $P_{1}, V_{1}$, and $I_{1}$ are fundamental frequency quantities and $V_{n}, I_{n}, \theta_{n}$, and $\delta_{n}$ are related to a frequency, $\mathrm{n}$, times the system power frequency. Because true power factor is always less than unity, it also holds that:

$$
\mathrm{PF}_{\text {total }} \leq \mathrm{DPF}
$$

In Equation (18), note that fundamental displacement power factor is the ratio between $\mathrm{P}_{\text {total }} / \mathrm{S}_{\text {total }}$ or $\mathrm{P}_{1} /\left(\mathrm{V}_{1} \mathrm{I}_{1}\right)$

\subsection{Voltage-related Parameters}


Crest factor, unbalance factor and flicker factor are intended for assessing dielectric stress, three-phase circuit balance, and source stiffness with regard to its capability of maintaining an adequate voltage regulation, respectively [2]

$$
\begin{gathered}
\text { crest factor }=\frac{\mathrm{V}_{\text {peak }}}{\mathrm{V}_{R m s}} \\
\text { Unbalance Factor }=\frac{|\mathrm{V}-|}{|\mathrm{V}+|} \\
\text { Flicker Factor }=\frac{\Delta \mathrm{V}}{|\mathrm{V}|}
\end{gathered}
$$

\section{Nonlinear Loads in Power Systems}

In a normal alternating current power system, the current varies sinusoidally at a specific frequency, usually 50 or 60 Hertz. When a linear electrical load is connected to the system, it draws a sinusoidal current at the same frequency as the voltage (though usually not in phase with the voltage).

Current harmonics are caused by non-linear loads [6]. When a non-linear load, such as a rectifier, is connected to the system, it draws a current that is not necessarily sinusoidal. The current waveform can become quite complex, depending on the type of load and its interaction with other components of the system.

Regardless of how complex the current waveform becomes, as described through Fourier series analysis, it is possible to decompose it into a series of simple sinusoids, which start at the power system fundamental frequency and occur at integer multiples of the fundamental frequency[7].

\section{Description of the industrial power supply system}

In figure 5. Outline of investigation industrial power supply system shown

System transformer TS $-\mathrm{S}_{\mathrm{nom}}=40 \mathrm{MVA}, \mathrm{V}_{\mathrm{sc}}=11 \%, \Delta \mathrm{P}_{\mathrm{sc}}=170 \mathrm{kw}, \mathrm{V}_{\text {high }}=110$

$\mathrm{kv}, \mathrm{V}_{\text {low }}=6 \mathrm{kv}$

Induction motors

$$
\text { M1 }-\mathrm{P}_{1 \text { nom }}=5 * 1.0=5 \mathrm{MW}, \cos \theta=0.85, \mathrm{k}_{\mathrm{st}}=5.0
$$

Induction motor capacitors $\mathbf{K 1}-\mathrm{Q}_{1 \mathrm{nom}}=5 * 0.5=2.5 \mathrm{MVAR}$

Switchable capacitor units $\mathbf{K} 2-\mathrm{Q}_{2 \mathrm{nom}}=3 * 1.2=3.6 \mathrm{MVAR}$

Linear load

$$
\text { S }_{\text {lin }} \text { P }=5.6 \mathrm{MW}, \cos \theta=0.85
$$

In this circuit we have harmonic numbers $(5,7,11,13,17,19,23,25)$

Each one has current like in table Table 1 below:

Table 1 - Harmonic currents of the variable frequency drives at $6 \mathrm{KV}$ bus

\begin{tabular}{|c|c|c|c|c|c|c|c|c|}
\hline Harmonic number(n) & 5 & 7 & 11 & 13 & 17 & 19 & 23 & 25 \\
\hline Harmonic current in (Amp.) & 37.5 & 32 & 21 & 19 & 1.8 & 1.4 & 5.4 & 4.8 \\
\hline
\end{tabular}


In the switchable capacitor units have a 3 reactive power each one has $1.2 \mathrm{MVAR}$. The results obtained when we use 1 or 2 or 3 of these reactive power and see the effect on harmonics in each case.

in other side, we have 5 capacitors related to the induction motor each one has a value of 0.5 MVAR. We use 4 or 3 or 2 or 1 of these capacitors and we saw the effect in the results. We has a 5 induction motor each one has a power equal to $\mathrm{P} 1_{\text {nom }}=1 \mathrm{MW}$. For example, if we use 4 of these reactive powers we must use 4 of the induction motors.

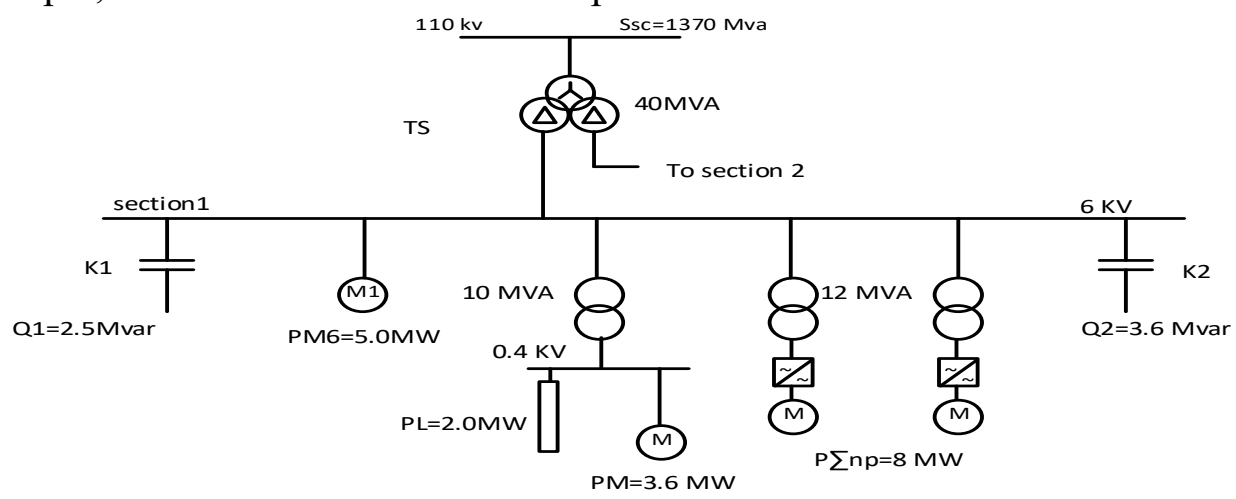

Supply system outline

Figure 5 - outline circuit diagram of the system

\section{Equivalent circuit and parameters of the supply system}

The equivalent circuit of the outline diagram shown in figure 6 below:

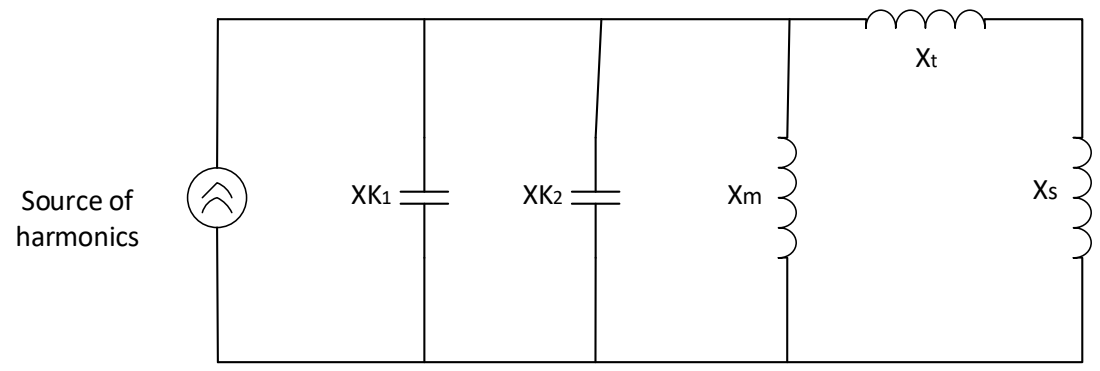

Figure 6 - Equivalent circuit of the outline diagram

Calculating $\mathrm{XK}_{2}$ by using the formula 22 below:

$$
\mathrm{XK}_{2}=\frac{\mathrm{V}_{\text {low }}^{2}}{\mathrm{Q} 2 \text { nom }}
$$


Where:

$\mathrm{Xk}_{2}$ - capacitive reactance of $\mathrm{K}_{2}$

$\mathrm{V}_{\text {low }}$ - nominal voltage in bus $6 \mathrm{KV}$

$\mathrm{Q} 2$ nom - reactive power of $\mathrm{K}_{2}$

$$
\mathrm{Xk}_{1}=\frac{\mathrm{V}_{\text {low }}^{2}}{\mathrm{Q} 1_{\text {nom }}}
$$

Where:

$\mathrm{XK}_{1}$ - capacitive reactance of $\mathrm{K}_{1}$

$\mathrm{Q} 1_{\text {nom }}$ - reactive power of $\mathrm{K}_{1}$

$$
\mathrm{Xt}_{\text {low }}=\mathrm{V}_{\mathrm{sc}} * \frac{\mathrm{V}_{\text {low }}^{2}}{\mathrm{~S}_{\text {nom }}}
$$

Where:

$\mathrm{Xt}_{\text {low }}$ - inductive reactance of transformer

$\mathrm{V}_{\mathrm{sc}}$ - short circuit voltage of transformer

$S_{\text {nom - nominal value of apparent power }}$

For split secondary transformer winding

$\mathrm{X}_{\text {th }}=\mathrm{Xt}_{\text {ow }} / 2$

$\mathrm{Xt}_{\text {low }}=\mathrm{X}_{\mathrm{th}}$

$\mathrm{Xt}_{\text {low } 1}=2 * \mathrm{Xt}_{\text {low }}$

Where:

$\mathrm{X}_{\text {tlow1 }}$ - inductive reactance of the transformer at low voltage winding

$\mathrm{X}_{\text {th }}$ - reactance of high voltage winding

$$
\mathrm{X}_{\mathrm{m}}=\frac{\mathrm{V}_{\text {low }}{ }^{2}}{\mathrm{~K}_{\mathrm{st}} * \frac{\mathrm{P}_{\mathrm{nom}}}{0.85}}
$$

Where:

$\mathrm{X}_{\mathrm{m}}$ - inductive reactance of motor

$\mathrm{P}_{\text {nom }}$ - active power of motor

$\operatorname{Cos} \theta-0.85$

$\mathrm{K}_{\mathrm{st}}-$ starting ratio

$$
\mathrm{Xs}_{110}=\frac{\mathrm{V}_{\mathrm{high}}^{2}}{\mathrm{~S}_{\mathrm{sc}}}
$$

Where: 
$\mathrm{Xs}_{110}$ - inductive reactance of source in bus $110 \mathrm{kv}$

$\mathrm{V}_{\text {high }}$ - nominal voltage in bus $110 \mathrm{kv}$

$\mathrm{S}_{\mathrm{sc}}$ - apparent power of bus $110 \mathrm{kv}$

Calculating the $\left(\mathrm{Xs}_{6}\right)$ in bus $6 \mathrm{kv}$ by the formula 27 below:

$$
\mathrm{Xs}_{6}=\mathrm{X} \mathrm{s}_{110} *\left(\frac{\mathrm{V}_{\text {low }}}{\mathrm{V}_{\text {high }}}\right)^{2}
$$

Where:

$\mathrm{Xs}_{6}$ - inductive reactance of source in bus $6 \mathrm{kV}$

Now equivalent circuit appears as below:

In figure 6 will add $X_{t}$ with $X_{s}$ as a series parameter resulting $X$ as shown in figure 7 below:

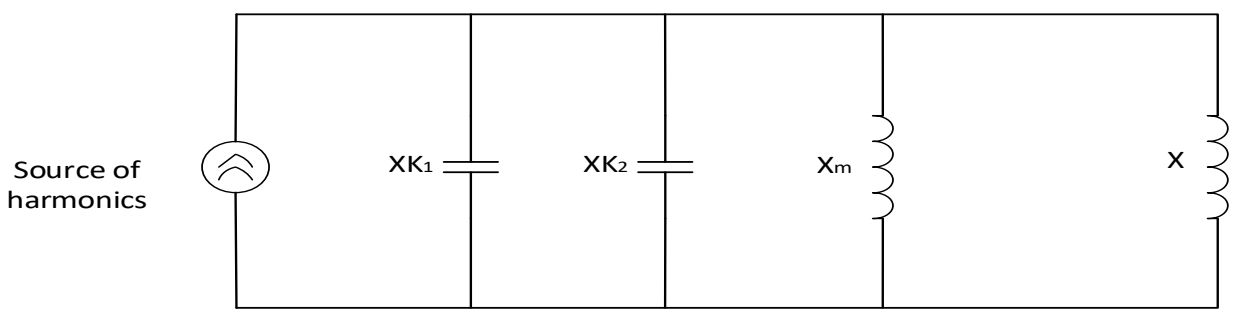

Figure 7 - Xt in series with XS the total be X

$\mathrm{X}$ in parallel with $\mathrm{Xm}$ the result be $\mathrm{X}_{\mathrm{p}}$ as shown in figure 8 below:

Source of harmonics

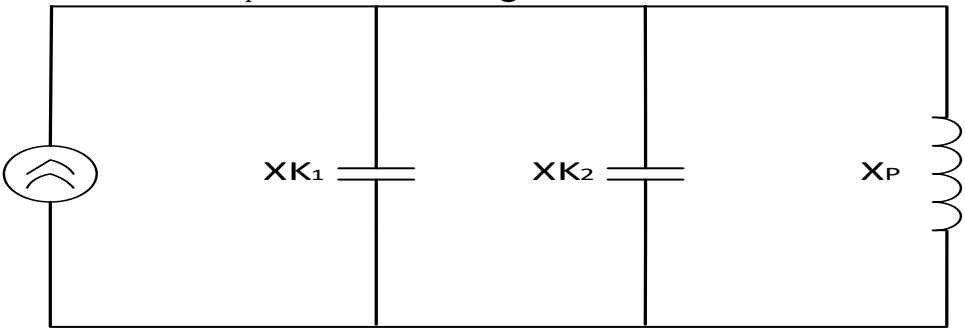

Figure 8 - X in parallel with $X m$ the total be $X p$

$\mathrm{Xk}_{1}$ in parallel with $\mathrm{Xk}_{2}$ the result be $\mathrm{Xk}_{\mathrm{p}}$ by using the formula 28

$$
\mathrm{Xk}_{\mathrm{p}}=\frac{\mathrm{Xk}_{1} * \mathrm{Xk}_{2}}{\mathrm{Xk}_{1}+\mathrm{Xk}_{2}}
$$

The equivalent circuit appear as shown in figure 9 below: 


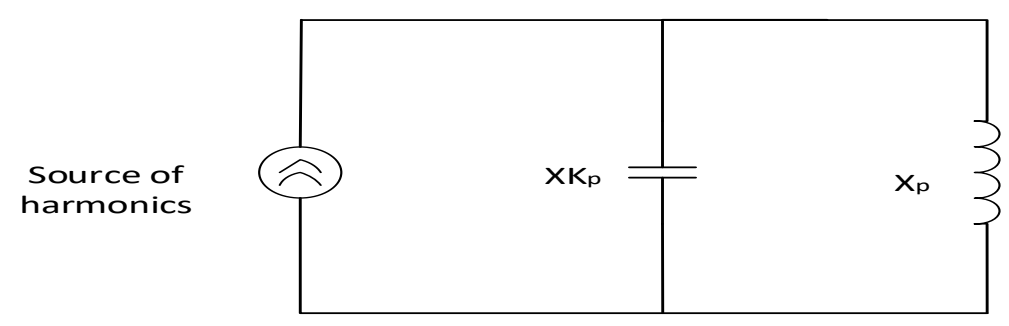

Figure $9-\mathrm{Xk}_{1}$ in parallel with $\mathrm{Xk}_{2}$ the result be $\mathrm{Xk}_{\mathrm{p}}$

$\mathrm{X}_{\mathrm{p}}$ in parallel with $\mathrm{Xk}_{\mathrm{p}}$ the result be $\mathrm{X}_{\text {total }}$ by using the formula 4.8 below:

$$
X_{\text {total }}=\left|\frac{\mathrm{Xk}_{\mathrm{p}} * \mathrm{X}_{\mathrm{p}}}{\mathrm{Xk}_{\mathrm{p}}-\mathrm{X}_{\mathrm{p}}}\right|
$$

\section{Harmonic analysis of the supply system}

\subsection{Equivalent circuit parameters for $Q 2{ }_{n o m}=3.6$ MVAR, $Q 1$ nom=}

\subsection{MVAR, P1 $1_{\text {nom }}=5$ MW}

In capacitor unit (K2) 3 capacitors with reactive power $\mathrm{Q} 2{ }_{\text {nom }}=3.6 \mathrm{MVAR}$, $\mathrm{Q} 1_{\text {nom }}=2.5 \mathrm{MVAR}, \mathrm{P} 1_{\text {nom }}=5 \mathrm{MW}$ the results are shown in table 2 below.

Table 2 - Equivalent reactance for harmonics in case of $\mathrm{Q} 2_{\mathrm{nom}}=3.6 \mathrm{MVAR}, \mathrm{Q} 1_{\mathrm{nom}}=2.5$ MVAR, $\mathrm{P} 1_{\text {nom }}=5 \mathrm{MW}$

\begin{tabular}{|c|c|c|c|c|c|c|c|c|c|}
\hline 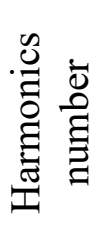 & 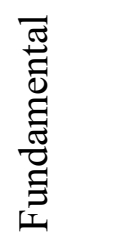 & 5 & 7 & 11 & 13 & 17 & 19 & 23 & 25 \\
\hline $\mathrm{XK}_{1}$ & 14.4 & 2.88 & 2.057 & 1.309 & 1.108 & 0.847 & 0.758 & 0.626 & 0.576 \\
\hline $\mathrm{XK}_{2}$ & 10 & 2 & 1.429 & 0.909 & 0.769 & 0.588 & 0.526 & 0.435 & 0.4 \\
\hline $\mathrm{Xt}$ & 0.149 & 0.743 & 1.04 & 1.634 & 1.931 & 2.525 & 2.822 & 3.416 & 3.713 \\
\hline $\mathrm{Xm}$ & 1.224 & 6.12 & 8.568 & 13.464 & 15.912 & 20.808 & 23.256 & 28.152 & 30.6 \\
\hline $\mathrm{Xs}$ & 0.026 & 0.131 & 0.184 & 0.289 & 0.342 & 0.447 & 0.499 & 0.604 & 0.657 \\
\hline $\mathrm{X}_{\mathrm{L}}$ & 0.153 & 0.765 & 1.071 & 1.682 & 1.988 & 2.6 & 2.906 & 3.518 & 3.823 \\
\hline $\mathrm{Xc}$ & 5.902 & 1.18 & 0.843 & 0.537 & 0.454 & 0.347 & 0.311 & 0.257 & 0.236 \\
\hline $\mathrm{X}_{\text {total }}$ & 0.157 & 2.172 & 3.968 & 0.788 & 0.588 & 0.401 & 0.348 & 0.277 & 0.252 \\
\hline
\end{tabular}

\subsection{Equivalent circuit parameters for $Q 22_{\text {nom }}=2.4$ MVAR,} Q1 ${ }_{\text {nom }}=2.5$ MVAR, P1 nom $=5$ MW

In capacitor unit $(\mathrm{K} 2) 2$ capacitors with reactive power $\mathrm{Q} 2_{\mathrm{nom}}=2.4 \mathrm{MVAR}$, $\mathrm{Q} 1_{\text {nom }}=2.5 \mathrm{MVAR}, \mathrm{P} 1_{\text {nom }}=5 \mathrm{MW}$ the results are shown in table 3 below. 
Table 3 - Equivalent reactance for harmonics in case of $Q 2_{\text {nom }}=2.4 \mathrm{MVAR}, \mathrm{Q} 1_{\text {nom }}=2.5$ MVAR, $\mathrm{P} 1_{\text {nom }}=5 \mathrm{MW}$

\begin{tabular}{|c|c|c|c|c|c|c|c|c|c|}
\hline 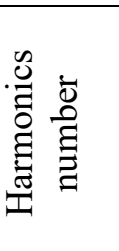 & 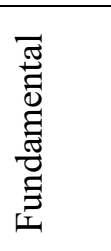 & 5 & 7 & 11 & 13 & 17 & 19 & 23 & 25 \\
\hline $\mathrm{XK}_{1}$ & 14.4 & 2.88 & 2.057 & 1.309 & 1.108 & 0.847 & 0.758 & 0.626 & 0.576 \\
\hline $\mathrm{XK}_{2}$ & 15 & 3 & 2.143 & 1.364 & 1.154 & 0.882 & 0.789 & 0.652 & 0.6 \\
\hline $\mathrm{Xt}$ & 0.149 & 0.743 & 1.04 & 1.634 & 1.931 & 2.525 & 2.822 & 3.416 & 3.713 \\
\hline $\mathrm{Xm}$ & 1.224 & 6.12 & 8.568 & 13.464 & 15.912 & 20.808 & 23.256 & 28.152 & 30.6 \\
\hline $\mathrm{Xs}$ & 0.026 & 0.131 & 0.184 & 0.289 & 0.342 & 0.447 & 0.499 & 0.604 & 0.657 \\
\hline $\mathrm{X}_{\mathrm{L}}$ & 0.153 & 0.765 & 1.071 & 1.682 & 1.988 & 2.6 & 2.906 & 3.518 & 3.823 \\
\hline $\mathrm{Xc}$ & 7.347 & 1.469 & 1.05 & 0.668 & 0.565 & 0.432 & 0.387 & 0.319 & 0.294 \\
\hline$X_{\text {total }}$ & 0.156 & 1.594 & 53.481 & 1.108 & 0.79 & 0.518 & 0.446 & 0.351 & 0.318 \\
\hline
\end{tabular}

\subsection{Equivalent circuit parameters for $Q 2_{n o m}=1.2 M V A R, ~ Q 1_{n o m}=2.5$} MVAR, P1 ${ }_{\text {nom }}=5$ MW

In capacitor unit (K2) 1 capacitor with reactive power $\mathrm{Q} 2_{\text {nom }}=1.2 \mathrm{MVAR}$, $\mathrm{Q} 1_{\text {nom }}=2.5 \mathrm{MVAR}, \mathrm{P} 1_{\text {nom }}=5 \mathrm{MW}$ the results shown in table 4 below.

Table 4 - Equivalent reactance for harmonics in case of $\mathrm{Q} 2_{\mathrm{nom}}=1.2 \mathrm{MVAR}, \mathrm{Q} 1_{\text {nom }}=2.5$ MVAR, $\mathrm{P} 1_{\text {nom }}=5 \mathrm{MW}$

\begin{tabular}{|c|c|c|c|c|c|c|c|c|c|}
\hline 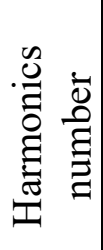 & 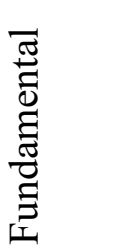 & 5 & 7 & 11 & 13 & 17 & 19 & 23 & 25 \\
\hline $\mathrm{XK}_{1}$ & 14.4 & 2.88 & 2.057 & 1.309 & 1.108 & 0.847 & 0.758 & 0.626 & 0.576 \\
\hline $\mathrm{XK}_{2}$ & 30 & 6 & 4.286 & 2.727 & 2.308 & 1.765 & 1.579 & 1.304 & 1.2 \\
\hline $\mathrm{Xt}$ & 0.149 & 0.743 & 1.04 & 1.634 & 1.931 & 2.525 & 2.822 & 3.416 & 3.713 \\
\hline $\mathrm{Xm}$ & 1.224 & 6.12 & 8.568 & 13.464 & 15.912 & 20.808 & 23.256 & 28.152 & 30.6 \\
\hline $\mathrm{Xs}$ & 0.026 & 0.131 & 0.184 & 0.289 & 0.342 & 0.447 & 0.499 & 0.604 & 0.657 \\
\hline $\mathrm{X}_{\mathrm{L}}$ & 0.153 & 0.765 & 1.071 & 1.682 & 1.988 & 2.6 & 2.906 & 3.518 & 3.823 \\
\hline
\end{tabular}




\begin{tabular}{|c|c|c|c|c|c|c|c|c|c|}
\hline $\mathrm{Xc}$ & 9.73 & 1.946 & 1.39 & 0.885 & 0.748 & 0.572 & 0.512 & 0.423 & 0.389 \\
\hline $\mathrm{X}_{\text {total }}$ & 0.155 & 1.26 & 4.659 & 1.865 & 1.2 & 0.734 & 0.622 & 0.481 & 0.433 \\
\hline
\end{tabular}

\section{Calculation of the voltage harmonics}

Calculating the voltages due to each harmonic by using the formula 30 below:

Where:

$$
\mathrm{V}_{\mathrm{n}}=\mathrm{I}_{\mathrm{n}} *\left(\mathrm{X}_{\text {total }}\right) * \sqrt{3}
$$

$\mathrm{V}_{\mathrm{n}}$ - voltage due to in each harmonic

$I_{n}$ - current of each harmonic

$\mathrm{X}_{\text {total }}$ - total impedance in each case

9.1 Voltage harmonics for $Q 2_{\text {nom }}=3.6 \mathrm{MVAR}, \mathrm{Q} 1_{\mathrm{nom}}=\mathbf{2 . 5}$

\section{MVAR, P1 nom=5 MW}

The results as shown in table 5 below:

Table 5 - Voltage harmonics for $\mathrm{Q} 2_{\text {nom }}=3.6 \mathrm{MVAR}, \mathrm{Q} 1_{\text {nom }}=2.5 \mathrm{MVAR}, \mathrm{P} 1_{\text {nom }}=5 \mathrm{MW}$

\begin{tabular}{|c|c|c|c|c|c|c|c|c|}
\hline $\begin{array}{c}\text { Harmonics } \\
\text { number }\end{array}$ & $\mathbf{5}$ & $\mathbf{7}$ & $\mathbf{1 1}$ & $\mathbf{1 3}$ & $\mathbf{1 7}$ & $\mathbf{1 9}$ & $\mathbf{2 3}$ & $\mathbf{2 5}$ \\
\hline $\mathbf{V}_{\mathbf{n}}$ & 141.05 & 219.916 & 28.652 & 19.36 & 1.249 & 0.843 & 2.589 & 2.092 \\
\hline
\end{tabular}

\subsection{Voltage harmonics for $Q 2_{\text {nom }}=2.4$ MVAR, $Q 1_{\text {nom }}=2.5$ MVAR} , $P 1_{\text {nom }}=5$ MW

The results as shown in table 6 below:

Table 6 - Voltage harmonics for $\mathrm{Q} 2_{\text {nom }}=2.4 \mathrm{MVAR}, \mathrm{Q} 1_{\text {nom }}=2.5 \mathrm{MVAR}, \mathrm{P} 1_{\text {nom }}=5 \mathrm{MW}$

\begin{tabular}{|c|c|c|c|c|c|c|c|c|}
\hline $\begin{array}{c}\text { Harmonics } \\
\text { number }\end{array}$ & $\mathbf{5}$ & $\mathbf{7}$ & $\mathbf{1 1}$ & $\mathbf{1 3}$ & $\mathbf{1 7}$ & $\mathbf{1 9}$ & $\mathbf{2 3}$ & $\mathbf{2 5}$ \\
\hline $\mathbf{V}_{\mathbf{n}}$ & 103.566 & $2.964 * 10^{3}$ & 40.289 & 25.985 & 1.616 & 1.082 & 3.286 & 2.647 \\
\hline
\end{tabular}

\subsection{Voltage harmonics for $Q 2_{\text {nom }}=1.2 \mathrm{MVAR}, \mathrm{Q} 1_{\mathrm{nom}}=2.5 \mathrm{MVAR}$}

\section{, $P 1_{\text {nom }}=5$ MW}

The results as shown in table 7 below:

Table 7 - Voltage harmonics for $\mathrm{Q} 2_{\mathrm{nom}}=1.2 \mathrm{MVAR}, \mathrm{Q} 1_{\text {nom }}=2.5 \mathrm{MVAR}, \mathrm{P} 1_{\text {nom }}=5 \mathrm{MW}$

\begin{tabular}{|c|c|c|c|c|c|c|c|c|}
\hline $\begin{array}{c}\text { Harmonics } \\
\text { number }\end{array}$ & $\mathbf{5}$ & $\mathbf{7}$ & $\mathbf{1 1}$ & $\mathbf{1 3}$ & $\mathbf{1 7}$ & $\mathbf{1 9}$ & $\mathbf{2 3}$ & $\mathbf{2 5}$ \\
\hline $\mathbf{V}_{\mathbf{n}}$ & 81.822 & 258.232 & 67.842 & 39.5 & 2.288 & 1.507 & 4.498 & 3.602 \\
\hline
\end{tabular}

\section{Calculation of the voltage harmonics in percentage}

Calculating the voltage harmonics in percentage by using the formula 31 below:

$$
\mathrm{V}_{\mathrm{n} \%}=\left(\mathrm{V}_{\mathrm{n}} / \mathrm{V}_{\text {low }}\right) * 100 \%
$$


Where:

$\mathrm{V}_{\mathrm{n} \%}$ - voltage harmonics in percentage

10.1 Voltage harmonics in percentage for $Q 2_{\text {nom }}=3.6 \mathrm{MVAR}$, Q1 ${ }_{\text {nom }}=2.5$ MVAR, P1 $_{\text {nom }}=5$ MW

The results as shown in table 8 below:

Table $8-\mathrm{V}_{\mathrm{n}}$ in all number of harmonics in case $\mathrm{Q} 2_{\mathrm{nom}}=3.6 \mathrm{MVAR}, \mathrm{Q} 1 \mathrm{nom}=2.5$ MVAR, $\mathrm{P} 1_{\text {nom }}=5 \mathrm{MW}$

\begin{tabular}{|c|c|c|c|c|c|c|c|c|}
\hline $\begin{array}{c}\text { Harmonics } \\
\text { number }\end{array}$ & $\mathbf{5}$ & $\mathbf{7}$ & $\mathbf{1 1}$ & $\mathbf{1 3}$ & $\mathbf{1 7}$ & $\mathbf{1 9}$ & $\mathbf{2 3}$ & $\mathbf{2 5}$ \\
\hline $\mathbf{V}_{\mathbf{n} \%}$ & 2.351 & 3.665 & 0.478 & 0.323 & 0.021 & 0.014 & 0.043 & 0.035 \\
\hline
\end{tabular}

\subsection{Voltage harmonics in percentage for $Q 2_{\text {nom }}=2.4 \mathrm{MVAR}$,}

\section{Q1 nom $=2.5$ MVAR , P1 nom $=5$ MW}

The results as shown in table 9 below:

Table $9-\mathrm{V}_{\mathrm{n} \%}$ in all number of harmonics in case $\mathrm{Q} 2_{\text {nom }}=2.4 \mathrm{MVAR}, \mathrm{Q} 1_{\text {nom }}=2.5$ MVAR, $\mathrm{P} 1_{\text {nom }}=5 \mathrm{MW}$

\begin{tabular}{|c|c|c|c|c|c|c|c|c|}
\hline $\begin{array}{c}\text { Harmonics } \\
\text { number }\end{array}$ & $\mathbf{5}$ & $\mathbf{7}$ & $\mathbf{1 1}$ & $\mathbf{1 3}$ & $\mathbf{1 7}$ & $\mathbf{1 9}$ & $\mathbf{2 3}$ & $\mathbf{2 5}$ \\
\hline $\mathbf{V}_{\mathbf{n} \%}$ & 1.726 & 49.404 & 0.671 & 0.433 & 0.027 & 0.018 & 0.055 & 0.044 \\
\hline
\end{tabular}

\subsection{Voltage harmonics in percentage for $Q 2_{\text {nom }}=1.2 \mathrm{MVAR}$, Q1 ${ }_{\text {nom }}=2.5$ MVAR, P1 nom $=5$ MW}

The results as shown in table 10 below:

Table 10 $-\mathrm{V}_{\mathrm{n} \%}$ in all number of harmonics in case $\mathrm{Q} 2_{\mathrm{nom}}=1.2 \mathrm{MVAR}, \mathrm{Q} 1_{\mathrm{nom}}=2.5$ MVAR, $\mathrm{P} 1_{\text {nom }}=5 \mathrm{MW}$

\begin{tabular}{|c|c|c|c|c|c|c|c|c|}
\hline $\begin{array}{c}\text { Harmonics } \\
\text { number }\end{array}$ & $\mathbf{5}$ & $\mathbf{7}$ & $\mathbf{1 1}$ & $\mathbf{1 3}$ & $\mathbf{1 7}$ & $\mathbf{1 9}$ & $\mathbf{2 3}$ & $\mathbf{2 5}$ \\
\hline $\mathbf{V}_{\mathbf{n} \%}$ & 1.364 & 4.304 & 1.131 & 0.658 & 0.038 & 0.025 & 0.075 & 0.06 \\
\hline
\end{tabular}

all results less than the standard requirements except in harmonic number 7 if using $\mathrm{Q}_{2 \text { nom }}=2.4 \mathrm{MVAR}$ the result exceed the standard requirements.

\section{Calculations of the THD voltage}

Calculating THD by using the formula 32 below:

$$
\mathrm{THD}_{v}=\sqrt{\mathrm{V}_{5 \%}{ }^{2}+\mathrm{V}_{7 \%}{ }^{2}+\mathrm{V}_{11 \%}{ }^{2}+\mathrm{V}_{13 \%}{ }^{2}+\mathrm{V}_{17 \%}{ }^{2}+\mathrm{V}_{19 \%}{ }^{2}+\mathrm{V}_{23 \%}{ }^{2}+\mathrm{V}_{25 \%}{ }^{2}}
$$

Where:

$\mathrm{THD}_{\mathrm{v}}$ - total harmonic distortion 
From $\mathrm{V}_{5 \%}$ to $\mathrm{V}_{25} \%$ - voltage harmonic in percentage from harmonic 5 to 25

At $\mathrm{Q}_{2 \text { nom }}=3.6 \mathrm{MVAR} \quad \mathrm{THD}_{\mathrm{V}}=4.393$

At $\mathrm{Q}_{2 \text { nom }}=2.4 \mathrm{MVAR} \quad \mathrm{THD}_{\mathrm{V}}=49.441$

At $\mathrm{Q}_{2 \text { nom }}=1.2 \mathrm{MVAR} \quad \mathrm{THD}_{\mathrm{V}}=4.702$

\section{Calculations of the frequency characteristics}

For calculating frequency characteristics we use the formula below:

$$
\mathrm{Z}_{(\mathrm{n})}=\left|\frac{\left(\mathrm{i} * \mathrm{X}_{\mathrm{L}} * \mathrm{n}\right)+\mathrm{R}_{\mathrm{L}}}{\left(\mathrm{R}_{\mathrm{L}}+\left(\mathrm{i} * \mathrm{X}_{\mathrm{L}} * \mathrm{n}\right)\right)+\mathrm{R}_{\mathrm{C}}+\frac{\mathrm{X}_{\mathrm{C}}}{\mathrm{in}}} *\left(\mathrm{R}_{\mathrm{C}}+\frac{\mathrm{X}_{\mathrm{C}}}{\mathrm{in}}\right)\right|
$$

Where:

$\mathrm{Z}_{(\mathrm{n})}$ - impedance at any harmonics frequency in ohm

$\mathrm{i}$ - imaginary sign

$\mathrm{X}_{\mathrm{L}}$ - inductive reactance in ohm

$\mathrm{X}_{\mathrm{c}}$ - capacitive reactance in ohm

$\mathrm{R}_{\mathrm{L}}$ - internal resistance of the inductor in ohm

$\mathrm{R}_{\mathrm{c}}$ - internal resistance of the capacitor in ohm

The values of $\mathrm{RL}$ and $\mathrm{RC}$ in the equivalent circuit are mainly depended on the equivalent resistance of supply system (transformer + outgoing lines) for RL and on the active power losses in the compensating capacitors. In such type of supply systems RL resistance are within $2 \ldots 8 \%$ ( depended on the specific equipment ) of the equivalent reactance and the capacitor active power losses in general are within $0.2 \ldots 1 \%$ ( depended on the specific capacitors). So, in the calculations the average readings for the investigated system have been taken in to account. Frequency characteristic is a continuous frequency dependence of the input impedance magnitude. In case we obtain current harmonic spectrum of a nonlinear load (as integer numbers 5 , 7 , and so on), we can calculate voltage harmonic magnitudes by multiplying these harmonic current magnitudes by impedance magnitudes in these harmonics. Peak of the frequency characteristic has no impact on the result of calculations except it is coincided with one of the available numbers of current harmonics. Triplen current harmonics cannot flow in three phase symmetrical circuit that has no neutrals connection (four wires) because these harmonics have the same phase shift in all phases. 


\subsection{Frequency characteristics when $Q 2_{\text {nom }}=3.6$ MVAR, $Q 1_{\text {nom }}=2.5 M V A R$}

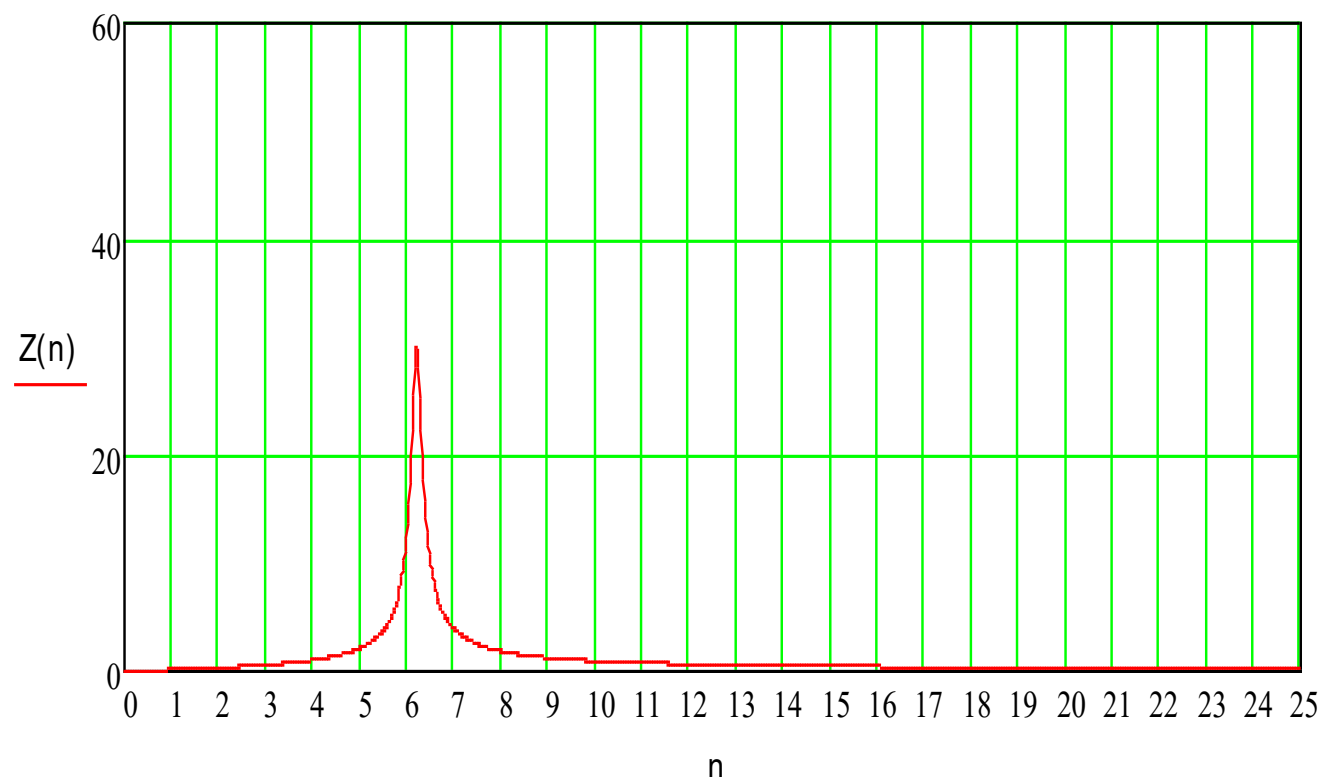

Figure 10 - Frequency characteristics when $\mathrm{Q} 2_{\text {nom }}=3.6 \mathrm{MVAR}, \mathrm{Q} 1_{\text {nom }}=2.5$ MVAR , $\mathrm{P} 1_{\text {nom }}=5 \mathrm{MW}$

12.2 Frequency characteristics when $Q 2_{\text {nom }}=2.4$ MVAR, $Q 1_{\text {nom }}=$ 2.5 MVAR, P1 $1_{\text {nom }}=5$ MW

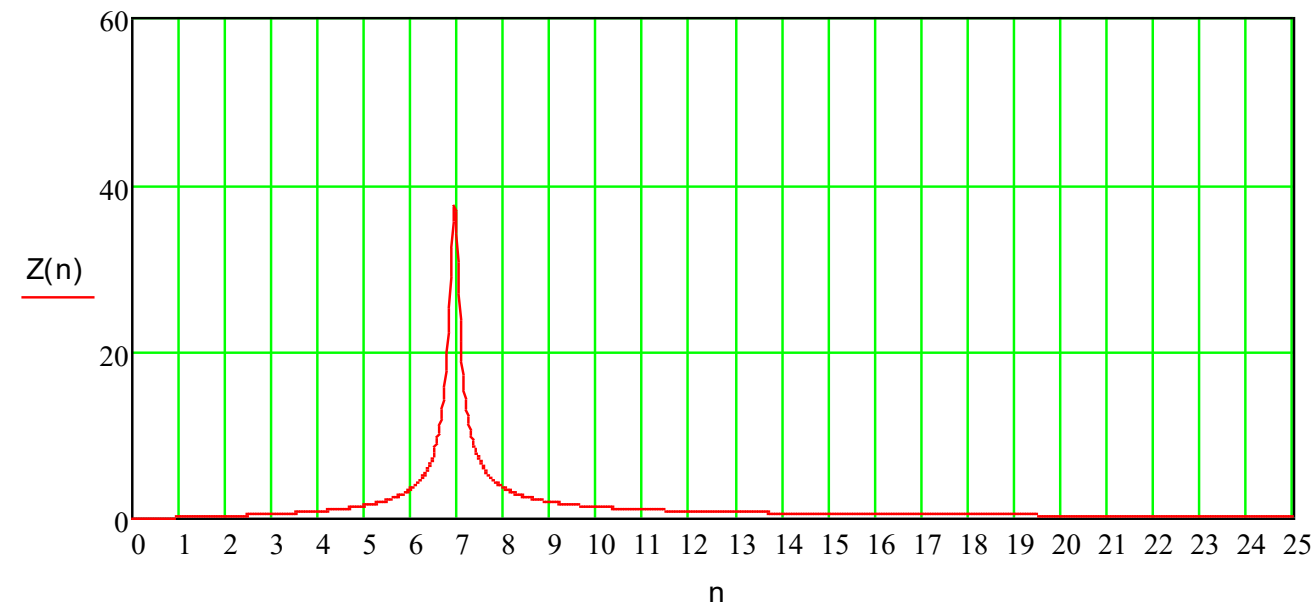


Figure 11 - Frequency characteristics when $\mathrm{Q} 2$ nom $=2.4 \mathrm{MVAR}, \mathrm{Q} 1_{\text {nom }}=2.5 \mathrm{MVAR}$,

$$
\mathrm{P} 1_{\text {nom }}=5 \mathrm{MW}
$$

12.3 Frequency characteristics when $Q 2_{\text {nom }}=1.2$ MVAR, $Q 11_{\text {nom }}=2.5$ MVAR,

$P 1_{\text {nom }}=5 \mathrm{MW}$

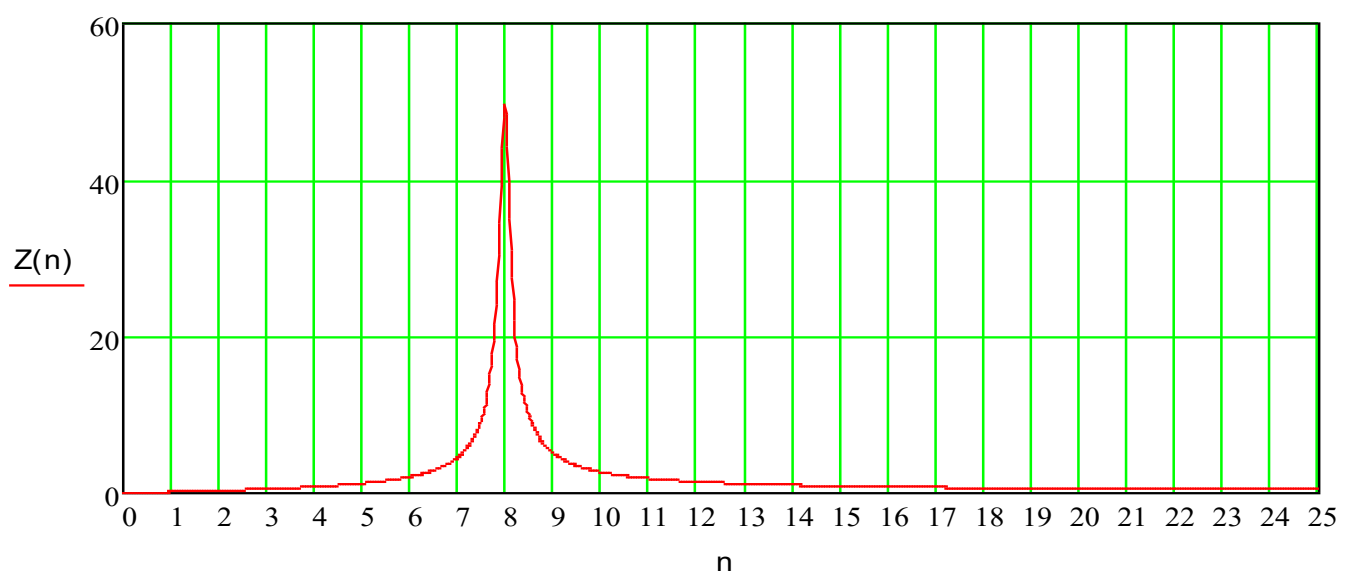

Figure 12 - Frequency characteristics When $\mathrm{Q} 2_{\text {nom }}=1.2 \mathrm{MVAR}, \mathrm{Q} 1_{\text {nom }}=2.5 \mathrm{MVAR}$,

$$
\mathrm{P} 1_{\text {nom }}=5 \mathrm{MW}
$$

By using the formula below:

Where:

$$
\mathrm{I}_{\mathrm{nc}}=\frac{\mathrm{V}_{\mathrm{n}}}{\mathrm{Xk} 2_{\mathrm{n}} * \sqrt{3}}
$$

$\mathrm{I}_{\mathrm{nc}}$ - current will flow in the capacitor in all harmonics number

$\mathrm{Xk} 2_{\mathrm{n}}$ - value of capacitance in each case in all harmonics

\subsection{Currents flow in the capacitor unit when Q2nom $=3.6 \mathrm{MVAR}$, Q1 ${ }_{\text {nom }}=2.5$ MVAR, P1 $1_{\text {nom }}=5 \mathrm{MW}$}

The result as in table 4.11 below:

Table 11 - Current will flow in the capacitor unit in case Q2 $2_{\text {nom }}=3.6 \mathrm{MVAR}, \mathrm{Q} 1_{\text {nom }}=2.5$ MVAR, $\mathrm{P} 1_{\text {nom }}=5 \mathrm{MW}$ 


\begin{tabular}{|c|c|c|c|c|c|c|c|c|c|}
\hline $\begin{array}{c}\text { Harmonics } \\
\text { number }\end{array}$ & fundamental & $\mathbf{5}$ & $\mathbf{7}$ & $\mathbf{1 1}$ & $\mathbf{1 3}$ & $\mathbf{1 7}$ & $\mathbf{1 9}$ & $\mathbf{2 3}$ & $\mathbf{2 5}$ \\
\hline $\mathbf{I}_{\text {cap }}$ & 346.41 & 40.718 & 88.878 & 18.197 & 14.531 & 1.226 & 0.925 & 3.438 & 3.019 \\
\hline
\end{tabular}

13.2 Currents flow in the capacitor unit when $Q 2_{\text {nom }}=2.4$ MVAR, Q1 ${ }_{\text {nom }}=2.5$ MVAR , P1 $1_{\text {nom }}=5 \mathrm{MW}$

The result as in table 12 below:

Table 12 - Current will flow in the capacitor unit in case $Q 2{ }_{\text {nom }}=2.4 \mathrm{MVAR}, \mathrm{Q} 1_{\text {nom }}=2.5$ MVAR, $\mathrm{P} 1_{\text {nom }}=5 \mathrm{MW}$

\begin{tabular}{|c|c|c|c|c|c|c|c|c|c|}
\hline $\begin{array}{c}\text { Harmonics } \\
\text { number }\end{array}$ & fundamental & $\mathbf{5}$ & $\mathbf{7}$ & $\mathbf{1 1}$ & $\mathbf{1 3}$ & $\mathbf{1 7}$ & $\mathbf{1 9}$ & $\mathbf{2 3}$ & $\mathbf{2 5}$ \\
\hline $\mathbf{I}_{\text {cap }}$ & 230.94 & 19.931 & 798.656 & 17.058 & 13.002 & 1.057 & 0.791 & 2.909 & 2.547 \\
\hline
\end{tabular}

13.3 Currents flow in the capacitor unit when $Q 2_{\text {nom }}=1.2$ MVAR, Q1 $1_{\text {nom }}=2.5$ MVAR , P1 $1_{\text {nom }}=5 \mathrm{MW}$

The result as in table 13 below:

Table 13 - Current will flow in the capacitor unit in case $\mathrm{Q} 2_{\text {nom }}=1.2$ MVAR, $Q 1_{\text {nom }}=2.5$ MVAR, $\mathrm{P} 1_{\text {nom }}=5 \mathrm{MW}$

\begin{tabular}{|c|c|c|c|c|c|c|c|c|c|}
\hline $\begin{array}{c}\text { Harmonics } \\
\text { number }\end{array}$ & fundamental & $\mathbf{5}$ & $\mathbf{7}$ & $\mathbf{1 1}$ & $\mathbf{1 3}$ & $\mathbf{1 7}$ & $\mathbf{1 9}$ & $\mathbf{2 3}$ & $\mathbf{2 5}$ \\
\hline $\mathbf{I}_{\text {cap }}$ & 115.47 & 7.873 & 34.788 & 14.362 & 9.882 & 0.749 & 0.551 & 1.991 & 1.733 \\
\hline
\end{tabular}

\section{4. $R m s$ currents flow in capacitor unit for the cases $\left(Q 2_{\text {nom }}=3.6\right.$} MVAR, Q2 ${ }_{\text {nom }}=2.4$ MVAR, Q2 ${ }_{\text {nom }}=1.2$ MVAR), Q1 $1_{\text {nom }}=2.5$ MVAR , $P 1_{\text {nom }}=5 \mathrm{MW}$

Using the formula below:

$$
I_{\text {Rmscap }}=\sqrt{I_{1 c}{ }^{2}+I_{5 c}{ }^{2}+I_{7 c}{ }^{2}+I_{11 c}{ }^{2}+I_{13 C^{2}}{ }^{2}+I_{17 C^{2}}+I_{19 C}{ }^{2}+I_{23 C}{ }^{2}+I_{25 c}{ }^{2}}
$$

Where:

$I_{R m s c a p}$ - the Rms current will flow in capacitor unit for all harmonics number From $I_{1 c}$ to $I_{25 c}$ - the current in each harmonic will flow in capacitor unit The result be:

When $\mathrm{Q}_{2 \text { nom }}=3.6 \mathrm{MVAR} \quad \mathrm{I}_{\mathrm{Rms} \text {.cap }}=360.725$ 
When $\mathrm{Q}_{2 \text { nom }}=2.4 \mathrm{MVAR} \quad \mathrm{I}_{\mathrm{Rms} . \text { cap }}=831.901$

When $\mathrm{Q}_{2 \text { nom }}=1.2$ MVAR $\quad \mathrm{I}_{\text {Rms.cap }}=122.136$

\section{Calculation of switchable capacitor loading}

Using $Q_{\text {nom(standard) }}$ from standard of capacitor in bus voltage (6 kv)

(Qnom(standard) $=1200 \mathrm{MVAR})$

The results obtained for either using 1 or 2 or 3 of these capacitors

Can be calculated $\mathrm{X}_{\text {cap.nom }}$ by using the formula below:

Where:

$$
\mathrm{X}_{\text {cap.nom }}=\frac{\mathrm{V}_{\text {nom }}{ }^{2}}{\mathrm{Q}_{\text {nom(standard) }}}
$$

$\mathrm{X}_{\text {cap.nom - nominal reactance of the capacitor }}$

Qnom(standard) - reactive power of the capacitor we choose it from standards

Calculating $\mathrm{I}_{\text {nom.cap }}$ by using the formula below:

$$
I_{\text {nom.cap }}=\frac{V_{\text {nom }}}{X_{\text {cap.nom }} * \sqrt{3}}
$$

Where:

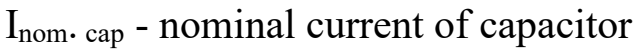

The result as follows:

$I_{\text {nom.cap }}$ for 3 capacitor $=346.41$

$I_{\text {nom.cap }}$ for 2 capacitor $=230.94$

$\mathrm{I}_{\text {nom.cap }}$ for 1 capacitor $=115.47$

For the analyzed capacitor unit by multiplying each value above by 1.3 we obtain permissible value of capacitor loading that has to be compared with IRMS as shown in equation 38 below:

The results as follows:

$$
\mathrm{I}_{\mathrm{RMS}} \leq 1.3 * \mathrm{I}_{\text {nom.cap }}
$$

\section{3 capacitor}

The value of $I R m s . c a p=360.725$ is smaller than the value of $\left(\mathrm{I}_{\text {nom.cap }} * 1.3\right)=450.333$

\section{2 capacitor}

The value of IRms.cap $=230.94$ is larger than the value of $\left(\mathrm{I}_{\text {nom.cap }} * 1.3\right)=300.222$

\section{1 capacitor}

The value of IRms.cap $=117.898$ is smaller than the value of $\left(\mathrm{I}_{\text {nom.cap }} * 1.3\right)=150.111$

\section{Calculations of voltage THD in the system with several connections of motor capacitors}

We can do the same calculations for several connection of motor capacitors, for several state of power conception in the supply system we have changed the required 
number of motors to support the manufacturing process, so capacity of the motor capacitors will be changed. According with this changing we have to analyses the change of voltage distortion in all cases these capacitors connection to the bus.

\section{Conclusion}

The analyzed power system supplies a complex load that consists of a linear part and nonlinear part as variable speed drives. Variable speed drives generate harmonics into the supply system. Two types of capacitor units are used within the power supply system for reactive power compensation. The $\mathrm{K} 1$ unit for $6 \mathrm{kV}$ induction motors reactive power compensation (there are five motors, each jointly switched with 0.5 MVAR capacitor) as well as the K2 unit that comprises three switched capacitor of 1.2 MVAR.

The impact of the switched capacitor units on the bus voltage distortion and on the capacitor units loading has been studied in the masterwork. European Standard EN50160 was used in all calculated cases as permissible levels of voltage distortion. The next possible capacitor units operating conditions have been studied and corresponding results obtained.

\section{Case 1 - Unit K1: Q=2.5 MVAR, Unit K2: $Q=3.6$ MVAR}

$\mathrm{THD}_{\mathrm{V}}$ and individual harmonic voltages do not exceed Standard permissible levels. Capacitor loading factor equal to $C_{I}=I_{R m s} / I_{\text {nom }}=1.04<1.3$

\section{Case 2 - Unit K1: Q=2.5 MVAR, Unit K2: Q =2.4 MVAR}

$\mathrm{THD}_{\mathrm{V}}=49.441 \%$ because of the considerable value of 7 -th harmonic voltage, that is equal to $49.404 \%$ and these values exceed Standard permissible levels (respectively equal to $8 \%$ and of $5 \%$ ).

Capacitor loading factor equal to $\mathrm{C}_{\mathrm{I}}=\mathrm{I}_{\mathrm{Rms}} / \mathrm{I}_{\text {nom }}=3.6>1.3$. The capacitor unit in this operating condition will be overloaded.

\section{Case 3 - Unit K1: Q=2.5 MVAR, Unit K2: Q =1.2 MVAR}

THD $_{\mathrm{V}}$ and individual harmonic voltages do not exceed Standard permissible levels. Capacitor loading factor equal to $\mathrm{C}_{\mathrm{I}}=\mathrm{I}_{\mathrm{Rms}} / \mathrm{I}_{\mathrm{nom}}=1.05<1.3$

As a result in case $\mathbf{1}$ and $\mathbf{3}$ for $\mathbf{K 2}$ are closest the standard value which is the

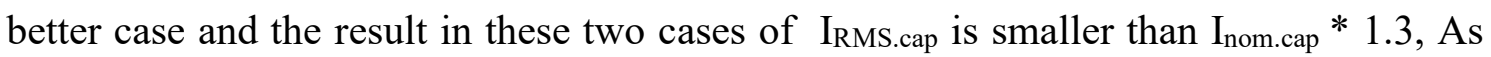
one can observe from the results of the power supply system harmonic analysis the change of reactive power compensating capacitor unit setup will draw varying the voltage distortion level on the supply system bus. The results of the power supply system analysis show possible ways to manage voltage harmonic distortion by appropriate selecting existing within the system capacitor units.

\section{Recommendation of using results of the masterwork}

Nowadays in Iraq electrical systems there is observed rapidly growth of nonlinear loads. Power electronic devices have become abundant today because of their capabilities for precise process control and energy savings benefits. However, they also 
bring drawbacks to electrical distribution systems. Harmonic currents increase the rms current in electrical systems and deteriorate the supply voltage quality. They stress the electrical network and potentially damage equipment. They may disrupt the normal operation of devices and increase operating costs. Capacitors are especially sensitive to harmonic components of the supply voltage due to the fact that capacitive reactance decreases as the frequency increases. In practice, this means that a relatively small percentage of harmonic voltage can cause a significant current to flow in the capacitor circuit. In the masterwork, a method of harmonic distortion analysis has been developed. The method makes it possible to analyze different outlines of the nonlinear loads supply system and elaborate the adequate means to minimize harmonic impact on another customer and electrical system equipment. The developed method and adequate Mathcad program will be useful means for designers that are faced to pay more and more attention to energy savings and improving the quality of the power supply.

\section{Future investigation}

In the future, the investigation can be expected development of possible ways of solving a harmonic problem that is presented under reactive power compensation of varying nonlinear loads in industrial power supply systems. Real capacitor has manufacturing tolerance $\Delta \mathrm{C}$ relative to the rating capacitance $\mathrm{C}_{\text {nom. }}$. It value depend on the manufacturing technology. Different manufacturers ensure different values of the tolerance. It value may vary within $-5 \ldots+10 \%$. So in a power supply system where we particularly know about type of used capacitors we can investigate the tolerance impact on the frequency characteristic.

\section{References}

1. C. Sankaran, Power quality, D.C. (C) 2002 by CRC Press LLC.

2. Francisco C. De La Rosa, Harmonics and Power systems.Distribution Control Systems, Inc. Hazelwood, Missouri, U.S.A.

3. Jon, A., Neville, R.W.: Power System Harmonics, 2nd ed.Wiley (2003).

4. Fourier, J.B.J.: Theorie analytique de la chaleur, Paris.

5. Bracewell R.N.: The Fourier Transform and Its Application, 3rd ed. Mc Graw.

6. H. W. Dommel, A. Yan, Shi Wei, "Harmonics from Transformer Saturation", IEEE Trans., Vol.PWRD-1, No.2, Apr 1986.

7. Fuchs,E.F.,Roesler, D.J. , Kovacs , K.P :Aging of electrical appliances due to harmonics of the power system voltage . IEEE Trans., Power delivery. TRWRD-1 (3), 1986. 